\title{
Awareness of occupational hazards and personal protective equipment use among dental hygienists
}

\author{
Hyun-Ju Choi ${ }^{1}$, Tae-Yoon Hwang ${ }^{2}$, Man-Joong Jeon ${ }^{2}$ \\ ${ }^{1}$ Department of Dental Hygiene, Daegu Health College, Daegu, Korea \\ ${ }^{2}$ Department of Preventive Medicine \& Public Health, Yeungnam University College of Medicine, Daegu, Korea
}

Received: May 23, 2018

Revised: October 15, 2018

Accepted: October 26, 2018

Corresponding author:

Tae-Yoon Hwang

Department of Preventive Medicine

\& Public Health, Yeungnam

University College of Medicine,

170, Hyeonchung-ro, Nam-gu,

Deagu 42415, Korea

Tel: +82-53-640-6954

Fax: +82-53-653-2061

E-mail: luke@ynu.ac.kr
Background: The aim of this study was to evaluate the awareness of occupational hazards and personal protective equipment use among dental hygienists (DHs).

Methods: A total of 271 self-administered questionnaires were obtained from $280 \mathrm{DHs}$ working at dental hospitals or clinics in Daegu and Gyeongsangbuk-do, Korea.

Results: The occupational hazards included work involving dust (94.1\%), volatile substances $(86.0 \%)$, noise $(97.0 \%)$, and light-curing units $(96.7 \%)$. The proportion of dental hygiene tasks that participants perceived as harmful were $42.4 \%, 51.7 \%, 9.2 \%$, and $31.4 \%$ in the same order as above. The proportion of participants who used dust-proof masks during work involving dust was $1.1 \%$. Those who wore gas-proof masks and gloves for work using volatile substances were $0.7 \%$ and $31.2 \%$, respectively. Participants who used goggles for work involving light-curing units were $31.0 \%$. None of the participants used ear plugs for work involving noise. A total of $22.9 \%$ of the participants recognized the Material Safety Data Sheet, while 79.7\% had never been educated about harmful work environments.

Conclusion: When compared to exposure status and perception of occupational hazards, the level of protective equipment use was very low. Extra measures to increase DHs' use of personal protective equipment are necessary.

Keywords: Dental hygienists; Occupations; Personal protective equipment

\section{Introduction}

Dental clinics and hospitals are exposed to various harmful substances depending on the nature of treatment. Many medical materials used in dental offices can cause abnormal and hypersensitivity reactions [1]. The risk of damage to hearing and vision is high, owing to harmful physical factors such as loud noises, radiation, and ultraviolet light [1].

Dental hygienists (DHs) in dental clinics and hospitals are exposed to various harmful physical and chemical elements during conservation and reinforcement work, such as calculus removal, diagnostic mouth radiography, impression acquisition, and production of temporary crowns. Hazardous exposures can lead to musculoskeletal disorders, eye damage, vibrationinduced neuropathy, hearing loss, and psychological stress [2-4]. Specifically, there are risks of eye damage due to direct blue light irradiation during resin preparation [5]. Harm may arise when chemicals are inhaled during prosthetic dentistry [6]. In addition, methyl methacrylate, which is used in dental cement, can induce mucous irritation, allergic reactions, hypersensitivity, asthma reactions, nerve symptoms, and skin diseases, among others [7]. Jang [8] reported that $46.5 \%$ of respondents complained of coughing due to alginate or stone dust inhalation and $61.1 \%$ of experienced respondents complained of coughing. Lee et al. [9] 
reported that noises from ultrasonic scalers, high- and low-speed handpieces, and dental suction affect the hearing of DHs.

Most existing studies have focused their investigations on either exposure to infectious diseases and its awareness, use of protective gear to prevent infection [10-12], or symptoms of musculoskeletal diseases [13-17].

Despite the known physical and chemical hazards of dental care environments, available research on DHs' awareness about, management of, and protection against these harmful environments is insufficient. DHs' work, like other hazardous tasks, requires personal protective equipment but the level of awareness of the hazardous work environment in dental offices is still low [18].

This study was conducted to identify DHs' awareness of the physically and chemically hazardous working conditions associated with dental care and to understand the need for appropriate protective equipment.

\section{Matrials and methods}

The study participants were DHs working in 6 dental hospitals and 35 dental clinics in Daegu and Gyeongsangbuk-do provinces. Those who performed reception duty or pregnant, were excluded. The dental hospitals and clinics were selected through convenient sampling. We obtained consent after providing an explanation of the study to the DHs and the corresponding dental hospitals and clinics.

Data collection was conducted between April 1, 2017 and April 20,2017 in the form of self-administered questionnaires. A total of 280 questionnaires were collected. After excluding 9 owing to unreliable responses, 271 were included in the final dataset. This study was approved by the institutional review board of the institution to which the researcher is affiliated (YU 2017-02-007$003)$.

Regarding general characteristics, demographic factors such as gender, age, and educational level, and work-related factors such as the type of working institution, as well as total duration of employment (in years), were investigated.

Work environment-related survey items were constructed based on a study by Choi [19], which adapted the Air Quality and Work Environment Symptom Survey developed by the National Institute for Occupational Safety and Health, to fit the Korean context. Work environment is an item that examines the frequency of work in dental hospitals and clinics that can prove harmful, including tasks that involve dust, volatile substances, noises, and light-curing units.

In order to identify the management characteristics of hazardous substances during dental work, items from a previous study by Kim and Choi [18] were used. Survey content included whether instructions are read before using dental materials, recognition of Material Safety Data Sheet (MSDS), DHs' knowledge about the potential harmfulness of dental materials, and awareness regarding the need for education.

The collected data were analyzed using IBM SPSS version 22.0 (IBM Co., Armonk, NY, USA) to compute frequencies and percentages of participants' general characteristics, awareness of health hazards in dental work, and the use of personal protective equipment.

\section{Results}

The most common age group was under 25 with 133 participants (49.1\%), followed by $26-30$ with 76 participants $(28.0 \%)$ and 31 or older with 62 participants $(22.9 \%)$. There were 227 college graduates (83.8\%) and 44 university graduates or above (16.2\%). A total of 144 participants (53.1\%) were from dental hospitals and 127 (46.9\%) were from dental clinics. Total career duration was 5 years or less for 168 participants $(62.0 \%)$, followed by 6 to 10 years for 55 participants $(20.3 \%)$, and more than 11 years for 48 participants $(17.7 \%)$.

Regarding the average number of patients seen per day, 94 participants $(34.7 \%)$ saw more than 51 patients, $89(32.8 \%)$ saw fewer than 30, and 88 (32.5\%) saw between 31 and 50. The use of eyewear among participants was considered: 137 participants (50.6\%) wore neither, $62(22.9 \%)$ wore contact lenses, 38 (14.0\%) wore glasses, and 34 (12.5\%) wore both (Table 1).

Among those involved in physically or chemically harmful work, 255 participants (94.1\%) performed work involving dust, 233 (86.0\%) volatile substances, 263 (97.0\%) noises, and 262 (96.7\%) light-curing units.

For work involving dust, 234 participants (91.8\%) were engaged in alginate mixing, 202 (79.2\%) in prosthodontics polishing and restoration, 202 (79.2\%) in tooth preparation, and $164(64.3 \%)$ in plaster mixing.

For the types of volatile substances used, 194 participants (83.2\%) used disinfectants, $166(71.2 \%)$ resin monomers, 120 (51.5\%) formocresol, and 111 (47.6\%) zinc oxide eugenol.

For the types of noises, 256 participants (97.3\%) used suction and air, 248 (94.3\%) operated with dental hand pieces, 119 (45.2\%) were exposed to the cries of young patients during treatments, and 62 (23.6\%) performed plaster trimming (Table 2).

Based on multiple responses, participants considered the following as occupational hazards: inhalation of volatile substances at work $(140 ; 51.7 \%)$; work involving dust (115; 
Table 1. General characteristic of the subjects

\begin{tabular}{|c|c|}
\hline Characteristic & No. $(\%)$ \\
\hline \multicolumn{2}{|l|}{ Age (yr) } \\
\hline$\leq 25$ & $133(49.1)$ \\
\hline $26-30$ & $76(28.0)$ \\
\hline $31 \leq$ & $62(22.9)$ \\
\hline \multicolumn{2}{|l|}{ Educational level } \\
\hline College graduate & 227 (83.8) \\
\hline University or above & 44 (16.2) \\
\hline \multicolumn{2}{|c|}{ Type of working institution } \\
\hline Dental clinic & $127(46.9)$ \\
\hline Dental hospital & $144(53.1)$ \\
\hline \multicolumn{2}{|l|}{ Total job carrier (yr) } \\
\hline$\leq 5$ & $168(62.0)$ \\
\hline $6-10$ & $55(20.3)$ \\
\hline $11 \leq$ & $48(17.7)$ \\
\hline \multicolumn{2}{|l|}{ No. of patients a day } \\
\hline$\leq 30$ & $89(32.8)$ \\
\hline $31-50$ & $88(32.5)$ \\
\hline $51 \leq$ & $94(34.7)$ \\
\hline \multicolumn{2}{|c|}{ Glasses or contact lens use } \\
\hline Glasses & $38(14.0)$ \\
\hline Contact lens & $62(22.9)$ \\
\hline Both & $34(12.5)$ \\
\hline None & $137(50.6)$ \\
\hline Total & $271(100.0)$ \\
\hline
\end{tabular}

$42.4 \%)$; working with specialized equipment such as lightcuring units $(85 ; 31.4 \%)$; and work involving noises $(25 ; 9.2 \%)$ (Table 3).

Four participants (1.1\%) responded that they wear dust-proof masks when performing work involving dust. Reasons for not wearing dust-proof masks included "being busy" (47; 52.3\%), "not necessary" (20; 22.3\%), "no protective equipment use guidelines" (13; 14.4\%), and "no protective equipment available" (4; 4.4\%).

Two participants $(0.7 \%)$ responded that they use gas-proof masks and $84(31.2 \%)$ responded that they use gloves when performing work using volatile substances. Reasons for not wearing protective equipment when working with volatile substances included: "being busy" (31; 42.5\%), "not necessary" (17; 23.3\%), and "no protective equipment use guidelines" (16; $21.9 \%)$.

None of the participants used ear plugs, which should be worn while performing work involving noises. Reasons for not wearing ear plugs included: "no protective equipment" (122; 56.3\%), "not necessary" (38; 17.9\%), "being busy" (37; 17.0\%), and "no protective equipment use guidelines" $(15 ; 6.9 \%)$.

When performing work involving light-curing units, 62
Table 2. Frequency of hazardous dental works the subjects involved $(\mathrm{n}=271)$

\begin{tabular}{lc}
\hline Hazardous dental work & No. $(\%)$ \\
\hline Work making dust & $255(94.1)$ \\
Type of work making dust & \\
$\quad$ Alginate mixing & $234(91.8)$ \\
Prosthodontics polishing and restoration & $202(79.2)$ \\
Tooth preparation & $202(79.2)$ \\
Plaster mixing & $164(64.3)$ \\
Others & $17(6.6)$ \\
Work using volatile substance & $233(86.0)$ \\
Type of volatile substance used & \\
Disinfectant & $194(83.2)$ \\
Resin monomer & $166(71.2)$ \\
Formocresol & $120(51.5)$ \\
Zinc oxide eugenol & $111(47.6)$ \\
Others & $21(9.0)$ \\
Work making noise & $263(97.0)$ \\
Type of noise made & \\
Use of suction and air & $256(97.3)$ \\
Use of dental hand piece & $248(94.3)$ \\
Cry of younger patient & $119(45.2)$ \\
Plaster trimming & $62(23.6)$ \\
Others & $6(2.3)$ \\
Work using light curing unit & $262(96.7)$ \\
\hline
\end{tabular}

Table 3. Dental works perceived to be hazardous by the subjects $(\mathrm{n}=271)$

\begin{tabular}{lc}
\hline Dental work & No. (\%) \\
\hline Work making dust & $115(42.4)$ \\
Work using volatile substance & $140(51.7)$ \\
Work making noise & $25(9.2)$ \\
Work using light curing unit & $85(31.4)$ \\
\hline
\end{tabular}

Values are based on multiple responses.

participants (31.0\%) responded that they wear protective goggles. Reasons for not wearing protective goggles included: "being busy" (62; 41.2\%), "no protective equipment" (54; 36.0\%), "not necessary" (18; 12.0\%), and no protective equipment use guidelines" (14; 10.0\%) (Table 4).

One hundred and thirty-eight participants (50.9\%) read the instructions before using dental material. The dental MSDS was recognized by 62 (22.9\%). Fifty-five participants $(20.3 \%)$ had some experience of education regarding occupational hazards. Of those who had not received any education on occupational hazards, 178 participants (82.4\%) intended to gain this knowledge if given the opportunity (Table 5). 
Table 4. Frequency of the subjects use protective equipment according to hazardous dental works and reasons for not use

\begin{tabular}{|c|c|c|c|c|}
\hline Item & Work making dust & $\begin{array}{l}\text { Work using volatile } \\
\text { substance }\end{array}$ & Work making noise & $\begin{array}{c}\text { Work using light curing } \\
\text { unit }\end{array}$ \\
\hline \multicolumn{5}{|l|}{ Rate of protective equipment use $\mathrm{e}^{\mathrm{a})}$} \\
\hline Mask (gas/dust proof) & $4(1.1)$ & $2(0.7)$ & - & - \\
\hline Goggles & - & - & - & $62(31.0)$ \\
\hline Ear plug & - & - & $0(0.0)$ & - \\
\hline Gloves & - & $84(31.2)$ & - & - \\
\hline \multicolumn{5}{|l|}{ Reason for not use } \\
\hline Being busy & $47(52.3)$ & $31(42.5)$ & $37(17.0)$ & $62(41.2)$ \\
\hline Not necessary & $20(22.3)$ & $17(23.3)$ & $38(17.9)$ & $18(12.0)$ \\
\hline No protective equipment & $4(4.4)$ & $5(6.8)$ & $122(56.3)$ & $54(36.0)$ \\
\hline No protective equipment use guideline & $13(14.4)$ & $16(21.9)$ & $15(6.9)$ & $14(10.0)$ \\
\hline Others & $2(2.2)$ & $4(5.5)$ & $4(1.9)$ & $1(0.7)$ \\
\hline
\end{tabular}

${ }^{a)}$ Values are presented as number (\%) and only in case of the corresponding harmful dental works.

Table 5. Characteristics related to management of hazardous dental work condition

\begin{tabular}{lr}
\hline Item & No. (\%) \\
\hline $\begin{array}{l}\text { Read the instruction before using } \\
\text { dental material }\end{array}$ \\
$\quad$ Yes & $138(50.9)$ \\
No & $133(49.1)$ \\
Recognition of MSDS & $62(22.9)$ \\
$\quad$ Yes & $209(77.1)$ \\
$\quad$ No & \\
Education experience on harmfulness & \\
of dental material & \\
$\quad$ Yes & $216(79.7)$ \\
$\quad$ No & \\
Intention to get education on \\
harmfulness of dental material ${ }^{\text {a) }}$ \\
Yes \\
$\quad$ No
\end{tabular}

MSDS, material safety data sheet.

${ }^{a}$ The respondents are 216 subjects who answered not having education experience.

\section{Discussion}

Owing to the diversification and specialization of dental care, DHs must perform various tasks in prosthetics, preservation, corrective care, and preventive care [20]. In the course of their work, DHs are consistently exposed to physically and chemically harmful environments [18]. This study was conducted to identify DHs' exposure to hazardous work environments and to examine their use of personal protective equipment.

The frequencies of physically and chemically harmful work involving dust, volatile substances, noises, and light-curing units were $94.1 \%, 86.0 \%, 97.0 \%$, and $96.7 \%$, respectively. In contrast, the degree of perceived harm were in the following order: work involving volatile substances that induce inhalation 51.7\%; work involving dust $42.4 \%$; work using specialized equipment such as light-curing units $31.4 \%$; and work involving noise $9.2 \%$. Hazard perception was lower than the hazardous work factors to which DHs are exposed to in the dental setting. In particular, the recognition of noise hazards was very low.

Among the participants, $1.1 \%$ responded that they wore dustproof masks while doing work involving dust. While $0.7 \%$ and $31.2 \%$ responded that they wore gas-proof masks and protective gloves, respectively, while doing work with volatile substances. None of the participants wore ear plugs while doing work involving noises. Moreover, only $31.0 \%$ wore protective goggles while doing work using light-curing units. Although "being busy" and "no protective gear" were common reasons for not using appropriate personal protective equipment, the fundamental reason relates to low awareness of work-related hazards.

None of the DHs wore earplugs. This can be attributed to low awareness of the dangers of noises in dental hospitals and clinics. In terms of workplace noises, the working environment standard for $\mathrm{DHs}$ is much lower than the 8-hour average of $90 \mathrm{~dB}$ prescribed by the Industrial Safety and Health Act. However, Kim et al. [21] reported that noises produced in dental offices may lead to noise-induced deafness. Park and Kim [22] also reported that noises in dental settings, affect the hearing and job performance of DHs.

Our study showed that only $22.9 \%$ of the participants were familiar with the MSDS, and only $20.3 \%$ were educated about the harmfulness of dental materials. These findings suggest that there is a lack of awareness about occupational hazards in the dental work environment. Contrarily, Jeong et al. [23] reported that while dental workers know about the need for basic protection, the compliance rate is low because of reasons such as increased 
cost of care, cumbersomeness during procedures, and low awareness about cross-contamination risks.

The Industrial Safety and Health Act of Korea [24] stipulates the responsibility of the government and accountability of the employer to maintain and promote workers' safety and health by preventing industrial accidents and creating a pleasant working environment. This minimum requirement aims to prevent occupational health injuries. Such measures are important and should be thoroughly complied with. In addition, efforts to establish and implement more stringent standards should be supported.

The best way to prevent occupational health injuries is to transform the working environment into one that causes no harm. However, changing the duties or hazardous factors involved in DHs' work is difficult. Therefore, it is important to use personal protective equipment while working. Ryu [25] reported that security goggles and facial protection pads should be used for eye and face protection against various physical and chemical hazards in the process of providing care. Also, it is recommended that $\mathrm{DHs}$ wear safety goggles because ultraviolet rays from the use of light-curing units in the examination room and dental laboratory can affect the eyes [19]. However, a study by Hwang [26] found that although the rate of using protective gloves and masks was high, the rate of using safety goggles was inadequate. Wearing personal protective gear is important as the dental setting increases aerosol risks to the membranes of the eyes, nose, or lips. Aerosols are difficult to identify with the naked eye, and there is a possibility of cross-contamination between patients and workers through invasive treatment. Supplementing policies relating to the use of personal protective equipment and continued education are needed. It was reported that $\mathrm{DHs}$ are aware of the need for noise reduction in dentistry but do not receive noise prevention training [22].

A limitation of this study is that it is difficult to generalize the results as it considered DHs only in Daegu and Gyeongsangbukdo provinces. Moreover, the study is also limited in that relationships between harmful factors and the induced symptoms have not been considered. In terms of hazardous factors, the perception of the study participants may differ from the actual working environment. Owing to the low rate of protective equipment use, the relationship between work characteristics of the subjects and the perceived degree of harmfulness could not be analyzed. Since all the subjects were female, gender differences in the level of safety and health awareness also could not be analyzed. Additionally, differences in safety and health awareness and participants' work hours or the time of exposure to hazardous factors were not examined.
The results of the study showed a lack of awareness of the intricacies of working with hazardous factors and a low rate of protective equipment utilization among participants. Training DHs about work-related hazardous risks and continued management of workplace health and safety are necessary.

\section{Conflicts of interest}

No potential conflicts of interest relevant to this article were reported.

\section{ORCID}

Hyun-Ju Choi, https://orcid.org/0000-0001-5770-367X

Tae-Yoon Hwang, https://orcid.org/0000-0001-9397-5314

Man-Joong Jeon, https://orcid.org/0000-0001-8255-6202

\section{References}

1. Goldman HS, Hartman KS, Messite J. Occupational hazards in dentistry. Chicago: Year Book Medical Publishers; 1984.

2. Leggat PA, Kedjarune U, Smith DR. Occupational health problems in modern dentistry: a review. Ind Health 2007;45:611-21.

3. Farahat SA, Rashed LA, Zawilla NH, Farouk SM. Effect of occupational exposure to elemental mercury in the amalgam on thymulin hormone production among dental staff. Toxicol Ind Health 2009;25:159-67.

4. Park KH, Kim HJ. The relationship between noise awareness, hearing ability, and dental hygiene performance in dental hygienists. J Korean Soc Dent Hyg 2015;15:11-7.

5. Farrier SL, Farrier JN, Gilmour AS. Eye safety in operative dentistry - a study in general dental practice. Br Dent J 2006;200:218-23.

6. Chugh A. Occupational hazards in prosthetic dentistry. Dentistry 2017;7:410.

7. Leggat PA, Kedjarune U. Toxicity of methyl methacrylate in dentistry. Int Dent J 2003;53:126-31.

8. Jang HJ. Work-related symptoms and recognition of industrial accident compensation insurance among dental hygienists [dissertation]. Seoul: Yonsei University; 2005. p. 13.

9. Lee JS, Han YS, Cho YS. The noise level assessment of dental equipment. J Dent Hyg Sci 2015;15:603-11.

10. Nam YS, Yoo JS, Park MS. A study on actual conditions for prevention of infections by dental hygienists. J Dent Hyg Sci 2007;7:1-7.

11. Park JH, Heo NS, Song HJ. A study of current infection control by dental hygienists and related factors. J Korean Soc 
Dent Hyg 2011;11:993-1003.

12. Kim HR, Park MR, Sung HJ, Jo CY, Ryu HG. Perception and implementation for dental infection control in Busan, Kyung Nam areas. J Korean Acad Dent Hyg 2012;14:11-21.

13. Lee SY, Ko HJ. Related factors of musculoskeletal symptoms of neck and shoulder among dental hygienists. J Korean Acad Dent Hyg 2011;13:385-95.

14. Kim MA, Seo HJ. Dental hygienists work on the impact of factors associated with musculoskeletal pain. J Dent Hyg Sci 2012;12:558-65.

15. Song K, Kim MJ. The study on musculoskeletal system pain management practice. J Korean Acad Dent Hyg 2013;15:7588.

16. Kim BT, Choi HY, Moon SJ. Research on the subjective symptoms of musculoskeletal disorders for dental hygienists in Daegu. Korean Soc Health Serv Manag 2014;8:121-30.

17. Moon AE. The relationship between working environment factors and stress and musculoskeletal disorders in dental hygienists. J Dent Hyg Sci 2015;15:472-9.

18. Kim HK, Choi SJ. Hazard communication of dental materials for dental hygienists in Daegu or Gyeongsangbuk-do province area.J Korean Soc Occup Environ Hyg 2015;25:506-15.

19. Choi JO. A health questionnaire survey on self reported symptoms of dental hygienists [dissertation]. Seoul: Hanyang University; 2008. p. 5.

20. Kim YS, Shin MW. A study on the current state and weight of dental hygienists' works. J Korean Acad Dental Hyg Edu 2008;8:161-75.

21. Kim KO, Kim HO, Park SH, Han YH, Um LS, Lee SM. Effects of dental treatment noise on the hearing of dental hygienists. J Korean Acad Dent Admin 2013;1:61- 76.

22. Park KH, Kim HJ. The relationship between noise awareness, hearing ability, and dental hygiene performance in dental hygienists. J Korean Soc Dent Hyg 2015;15:11-7.

23. Jeong MK, Lee JY, Kang YJ. A study on the knowledge and attitude of dental hygienists for infection control in dental clinic. J Korean Soc Dent Hyg 2010;10:935-45.

24. Ministry of Employment and Labor. Occupational safety and health act [Internet]. Sejong: Ministry of Employment and Labor; 2017 [cited 2018 May 23]. http://www.law.go.kr/ lsInfoP.do?lsiSeq=193408\&ef Yd=20171019\#0000

25. Ryu MH. Cross-infection in dental clinic and infection control. J Namseoul Univ 2005;11:157-72.

26. Hwang JH. Knowledge and compliance with infection control among dental hygienists [dissertation]. Seoul: Yonsei University; 2008. p. 21-2. 